\title{
Effect of Excess Temperature above Liquidus of Lead-Free Solders on Wetting Time in a Wetting Balance Test
}

\author{
Tadashi Takemoto and Makoto Miyazaki* \\ Collaborative Research Center for Advanced Science and Technology, Osaka University, Suita 565-0871, Japan
}

\begin{abstract}
A wetting test was conducted using a wetting balance tester to evaluate the wettability of $\mathrm{Sn}-\mathrm{Ag}$ and $\mathrm{Sn}-\mathrm{Zn}$ lead-free solders with the addition of bismuth or indium up to 25 mass $\%$. The base metal and flux used were oxygen-free high-conductivity copper and rosin-based flux containing 0.2 mass $\% \mathrm{Cl}$ and 35 mass $\%$ solid rosin diluted with isopropyl alcohol. The wetting time decreased with increases in the amount of additional elements at a fixed test temperature. The wetting force had only a slight dependence on the element content; $\mathrm{Sn}-\mathrm{Zn}$ alloys exhibited less wetting force than $\mathrm{Sn}-\mathrm{Ag}$. The plots between the excess temperature above liquidus, (test temperature)-(liquidus), and wetting time correlated well. An increase in the excess temperature decreased the wetting time, indicating that the wetting time is closely controlled by the temperature-rising stage of the wetting test specimen. Therefore, a comparison of the contact angles is recommended for precisely evaluating the wettability on lead-free solders. The interfacial tension between the soldering flux and molten solder was measured by a simple method using a wetting balance tester to obtain the contact angle from the wetting balance test. The calculated contact angle in Sn-Ag system solders is smaller than that in $\mathrm{Sn}-\mathrm{Zn}$ system solders, indicating that $\mathrm{Sn-Ag}$ system solders exhibit superior wettability.
\end{abstract}

(Received November 21, 2000; Accepted March 22, 2001)

Keywords: lead-free solder, wetting time, melting temperature, tin-silver-bismuth alloy, tin-silver-indium alloy, contact angle, wetting balance

\section{Introduction}

Microsoldering has become a key technology for assembling high-density electronic wiring boards. ${ }^{1-3)}$ Conventional $\mathrm{Sn}-\mathrm{Pb}$ eutectic solder has been widely used due to its excellent wettability and appropriate melting temperature; however, the use of lead has gained attention ${ }^{4-8)}$ because the waste of assembled boards may cause environmental problems due to their toxicity. To substitute $\mathrm{Sn}-\mathrm{Pb}$ solder for the lead-free, the candidate alloys should have wettability and melting temperature ranges similar to an $\mathrm{Sn}-\mathrm{Pb}$ eutectic. $\left.{ }^{9}\right)$ Many studies have been performed on a worldwide scale to develop new lead-free solders that meet this demand. However, no alloys have yet been found that exhibit a performance similar or superior to the $\mathrm{Sn}-\mathrm{Pb}$ eutectic. Two eutectic solder systems, $\mathrm{Sn}-\mathrm{Ag}$ and $\mathrm{Sn}-\mathrm{Zn}$, are the basic alloys that provide a melting temperature range similar to the $\mathrm{Sn}-\mathrm{Pb}$ eutectic at $456 \mathrm{~K}{ }^{10}$ ) The addition of bismuth and/or indium is effective to lower the melting temperature. ${ }^{11)}$ Wettability is one of the most important characteristics in substitution solders. The wettability was evaluated by a wetting balance test, wherein the short wetting time and high wetting force were considered to be excellent. ${ }^{3)}$ The test was convenient for evaluating the activity of soldering flux as well as the effect of impurities in $\mathrm{Sn}-\mathrm{Pb}$ eutectic solder under fixed conditions. However, the applicability of the method for lead-free solders should be further investigated because lead-free solder alloys have different melting temperature ranges. The method includes the temperature increase stage of a specimen during the test because the wetting time obtained by a wetting balance test is closely related to the temperature rise of the specimen. ${ }^{12)}$

The wetting test by a wetting balance has recently become popular, even though the reflow microsoldering process has become the major electronic assembly technology for high density surface mounting. The usual reflow process has a preheating stage before the melting temperature of solder is

*Graduate Student, Osaka University. Present address: Oki Electric Co. Ltd., Takasaki, Japan. reached; the process requires several minutes to make solder joints sound. The wetting balance test is convenient for evaluating the solderability in the flow process that makes solder joints by contacting molten solder with solder lands for several seconds. The spread tests prescribed by JIS Z 3197 and ISO 9455 correspond to the reflow process and the wetting balance test corresponds to the flow process. The present study seeks to clarify the effect of the melting temperature of lead-free solders on the wettability and applicability of the wetting balance test, and to investigate the effect of the addition of bismuth and indium into $\mathrm{Sn}-\mathrm{Ag}$ and $\mathrm{Sn}-\mathrm{Zn}$ systems on the wettability.

\section{Materials and Experimental}

The solder alloys used were four basic ternary alloys based on $\mathrm{Sn}-3.5 \mathrm{Ag}$ and $\mathrm{Sn}-\mathrm{Zn}$ with bismuth or indium. The nominal chemical compositions and melting temperature ranges are given in Table 1. The silver content in the $\mathrm{Sn}-\mathrm{Ag}$ system was maintained at a constant value of 3.5 mass $\%$ irrespective of the content of additional elements. The zinc content in the $\mathrm{Sn}-\mathrm{Zn}$ system was decreased by the addition of bismuth or indium according to the literature ${ }^{13,14)}$ to obtain the tin primary phase. The liquidus temperature was measured by the cooling stage of differential thermal analysis (DTA), and the solidus temperature was measured by differential scanning calorimetry (DSC) of the heating stage. Several alloys showed a low melting point at the heating stage of DSC, as indicated by an asterisk $\left(^{*}\right)$ in Table 1 . The equivalent melting temperature of the $\mathrm{Sn}-\mathrm{Pb}$ eutectic could not be obtained by adding bismuth and indium into the $\mathrm{Sn}-\mathrm{Ag}$ system; however, the SnZn system exhibited a similar temperature range when about 5 mass\% of bismuth or indium was added. It is apparent that an excessive addition of these elements resulted in a melting temperature lower than the $\mathrm{Sn}-\mathrm{Pb}$ eutectic temperature.

The base metal for the wetting test was an oxygen-free high-conductivity copper plate (C 1020). Its size for the wetting balance test was $50 \mathrm{~mm}$ long, $5 \mathrm{~mm}$ wide and $0.5 \mathrm{~mm}$ 
Table 1 Nominal chemical compositions of solders used, mass $\%$.

\begin{tabular}{|c|c|c|c|}
\hline Solder system & Solder composition & Liquidus $(\mathrm{K})$ & Solidus (K) \\
\hline $\mathrm{Sn}-\mathrm{Ag}$ & Sn-3.5Ag (eutectic) & 494 & 494 \\
\hline \multirow{5}{*}{$\mathrm{Sn}-\mathrm{Ag}-\mathrm{Bi}$} & $\mathrm{Sn}-3.5 \mathrm{Ag}-5 \mathrm{Bi}$ & 487 & $468^{*}$ \\
\hline & $\mathrm{Sn}-3.5 \mathrm{Ag}-7.5 \mathrm{Bi}$ & 485 & $458^{*}$ \\
\hline & $\mathrm{Sn}-3.5 \mathrm{Ag}-10 \mathrm{Bi}$ & 481 & $399^{* *}$ \\
\hline & $\mathrm{Sn}-3.5 \mathrm{Ag}-15 \mathrm{Bi}$ & 475 & $401^{* *}$ \\
\hline & $\mathrm{Sn}-3.5 \mathrm{Ag}-20 \mathrm{Bi}$ & 467 & $402^{* *}$ \\
\hline \multirow{5}{*}{$\mathrm{Sn}-\mathrm{Ag}-\mathrm{In}$} & $\mathrm{Sn}-3.5 \mathrm{Ag}-5 \mathrm{In}$ & 485 & 460 \\
\hline & $\mathrm{Sn}-3.5 \mathrm{Ag}-10 \mathrm{In}$ & 477 & $383^{* *}$ \\
\hline & Sn-3.5Ag-15 In & 469 & $383^{* *}$ \\
\hline & $\mathrm{Sn}-3.5 \mathrm{Ag}-20 \mathrm{In}$ & 460 & $383^{* *}$ \\
\hline & $\mathrm{Sn}-3.5 \mathrm{Ag}-25 \mathrm{In}$ & 449 & $383^{* *}$ \\
\hline $\mathrm{Sn}-\mathrm{Zn}$ & Sn-8.8Zn (eutectic) & 473 & 473 \\
\hline \multirow{4}{*}{$\mathrm{Sn}-\mathrm{Zn}-\mathrm{Bi}$} & $\mathrm{Sn}-8.2 \mathrm{Zn}-5 \mathrm{Bi}$ & 465 & 460 \\
\hline & $\mathrm{Sn}-7.5 \mathrm{Zn}-10 \mathrm{Bi}$ & 460 & 436 \\
\hline & $\mathrm{Sn}-7.0 \mathrm{Zn}-15 \mathrm{Bi}$ & 455 & $399^{* *}$ \\
\hline & $\mathrm{Sn}-6.3 \mathrm{Zn}-20 \mathrm{Bi}$ & 449 & $399^{* *}$ \\
\hline \multirow{5}{*}{$\mathrm{Sn}-\mathrm{Zn}-\mathrm{In}$} & Sn-7.9Zn-5In & 462 & 448 \\
\hline & $\mathrm{Sn}-7.0 \mathrm{Zn}-10 \mathrm{In}$ & 456 & $377^{* *}$ \\
\hline & Sn-6.2Zn-15In & 449 & $377^{* *}$ \\
\hline & Sn-5.3Zn-20In & 441 & $377^{* *}$ \\
\hline & $\mathrm{Sn}-4.4 \mathrm{Zn}-25 \mathrm{In}$ & 435 & $377^{* *}$ \\
\hline $\mathrm{Sn}-\mathrm{Pb}$ & $\mathrm{Sn}-37 \mathrm{~Pb}$ (eutectic) & 456 & 456 \\
\hline
\end{tabular}

${ }^{*}$ : with small DSC peak in heating stage ${ }^{* *}$ : with low temperature reaction.

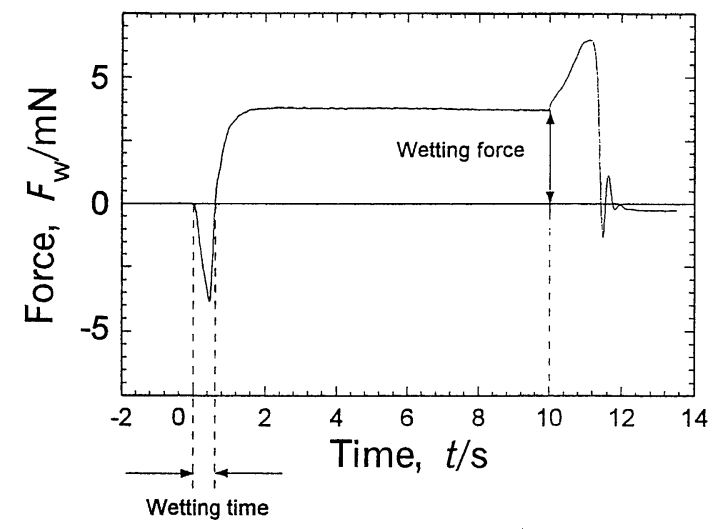

Fig. 1 Typical wetting curve obtained by a wetting balance test.

thick; the size for the spread test was $45 \mathrm{~mm}$ square and $0.4 \mathrm{~mm}$ thick. The specimens were cleaned prior to the test in $5 \% \mathrm{HCl}$ aqueous solution for $30 \mathrm{~s}$ and then rinsed in tap water and dried using acetone. A rosin-base flux containing $0.2 \%$ with $35 \%$ solid rosin was used in the wetting test and the solvent was isopropyl alcohol.

The wetting balance test can be used to obtain the dynamic process of wetting by measuring the force that acts between the immersing specimen and molten solder. The typical wetting curve is indicated in Fig. 1. The wetting force was measured automatically in the present study by a computer with a sampling rate of $0.01 \mathrm{~s}$. The wetting time and the wetting force are defined in Fig. 1; the wetting time was measured without compensation of the buoyancy force. The wetting force is the force measured after immersion for $10 \mathrm{~s}$; it was also measured without compensation of the buoyancy force. The buoyancy force was about $0.4 \mathrm{mN}$ for the $\mathrm{Sn}-\mathrm{Pb}$ eutectic. The immersion rate, depth, and time were $4 \mathrm{~mm} / \mathrm{s}, 2 \mathrm{~mm}$, and $10 \mathrm{~s}$. The test temperature was taken as the molten solder temperature $4 \mathrm{~mm}$ under the surface.

The spread test was conducted according to the method specified by JIS Z 3197 and ISO 9455. The test temperature was taken as the maximum temperature of molten solder reached on the copper base plate. The volume of solder used was fixed at $0.07 \mathrm{~mm}^{3}$, and the volume was calculated by the weight of the solder under the assumption that no density change occurred thorough alloying.

To discuss the wetting force, the contact angle, parameter for evaluating wettability, was calculated by the interfacial tension, which was measured by the simple measurement established by Miyazaki et al. ${ }^{15)}$ using a wetting balance.

\section{Results and Discussions}

Figure 2 shows the effect of the amount of additional elements and the test temperature on the wetting time in the wetting balance test. Similar tendencies were obtained in all alloys; the increase in the amount of additional elements and an increase in the test temperature reduced the wetting time. The wetting time was particularly reduced by the increase in the additional elements. The differences in wettability depending on the solder composition is not clear in Fig. 2. Okamoto et $a l .{ }^{12)}$ indicated that temperature increase in specimens are closely related to the wetting time because the wetting front climbs upward along the specimen after the temperature has reached the critical point at which wetting occurs. Therefore, the wetting curve corresponds to the temperature increase of the wetting front of a specimen. An immersed specimen is rapidly heated by conduction after contact with molten solder, whereas the contacted molten solder cools down due to conduction toward the copper specimen. Thus, the molten solder crystallizes around the immersed specimen at low temperatures even after an immersion test time of $10 \mathrm{~s}$. The solidified solder was grossly attached at the tip of the specimen after the test on $\mathrm{Sn}-3.5 \mathrm{Ag}$ solder at $498 \mathrm{~K}$, just $4 \mathrm{~K}$ over the $\mathrm{Sn}-\mathrm{Ag}$ eutectic temperature. This condition is indicated by the upward arrows in Fig. 2.

The wetting characteristics of a wetting balance test can be explained by assuming the solidification of solder at the tip of an immersed specimen. If the test temperature is fixed irrespective of the melting temperature of the solder, any excess temperature above the melting temperature is significant in regard to solidification of the solder just after contact with an immersed specimen. The solidification of molten solder occurs easily in solder with a higher melting temperature because the temperature is only slightly above the liquidus temperature, whereas in alloys with a low melting temperature, the temperature of the specimen tip will exceed the liquidus temperature during the test and the wetting then proceeds more rapidly even if solidification occurs just after immersion.

Figure 3(a) shows the plots between the wetting time and the excess temperature above liquidus, ((test temperature)(liquidus temperature), $\Delta T_{\mathrm{L}}$ ). As clearly indicated, the increase in the excess temperature decreased the wetting time. Figure 3(b) shows the plots between the wetting time and the excess temperature above solidus, ((test temperature)(solidus temperature), $\Delta T_{\mathrm{S}}$ ). These plots exhibit greater scattering than the plots in Fig. 3(a), because the solidus becomes almost constant irrespective of the content of elements due to 

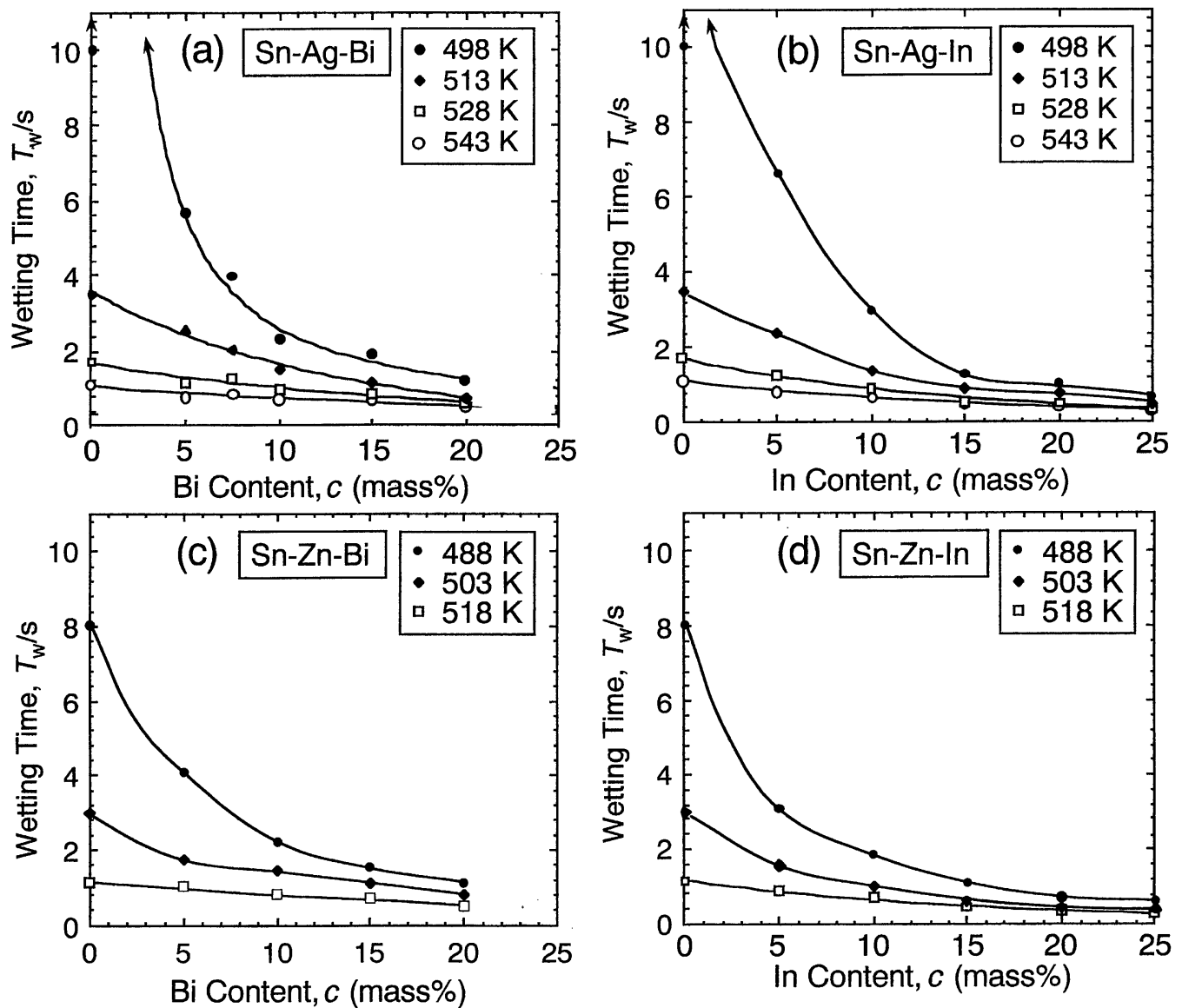

Fig. 2 Effect of amount of content of additional elements and test temperature on wetting time, (a) $\mathrm{Sn}-\mathrm{Ag}-\mathrm{Bi}$, (b) $\mathrm{Sn}-\mathrm{Ag}-\mathrm{In}$, (c) $\mathrm{Sn}-\mathrm{Zn}-\mathrm{Bi}$ and (d) $\mathrm{Sn}-\mathrm{Zn}-\mathrm{In}$.

the appearance of the low-temperature eutectic reaction. The plots between the wetting time and $\Delta T_{\mathrm{L}}$ showed a good relationship, with the rise in $\Delta T_{\mathrm{L}}$ drastically reducing the wetting time; therefore, the temperature rise, i.e. the cooling by immersion of a cold specimen, could greatly influence the wetting time. This data indicates that the wetting time obtained by the wetting balance test can explain the temperature rise process of a specimen.

Figure 4 shows an example of the wetting force measured at $513 \mathrm{~K}$ and $503 \mathrm{~K}$ for $\mathrm{Sn}-\mathrm{Ag}$ and $\mathrm{Sn}-\mathrm{Zn}$, respectively. The measured wetting force was maximum at $5 \% \mathrm{Bi}$ in $\mathrm{Sn}-\mathrm{Ag}-$ $\mathrm{Bi}$, was almost constant in $\mathrm{Sn}-\mathrm{Ag}-\mathrm{In}$, slightly decreased with the $\mathrm{Bi}$ content in $\mathrm{Sn}-\mathrm{Zn}-\mathrm{Bi}$, and was minimum at $5 \%$ In in $\mathrm{Sn}-\mathrm{Zn}-\mathrm{In}$. The wetting force is a product of the interfacial tension between flux and solder and the contact angle. ${ }^{3)}$

$$
F_{\mathrm{w}}=\gamma \cdot \cos \theta-\rho g V \text {. }
$$

Where

$$
\begin{aligned}
& F_{\mathrm{w}} \text { : wetting force } \\
& \gamma: \text { interfacial tension between flux and solder } \\
& \theta: \text { contact angle } \\
& \rho: \text { density } \\
& g: \text { gravity } \\
& V: \text { immersion volume of specimen }
\end{aligned}
$$

If the interfacial tension between the flux and solder during soldering is known, the contact angle can be derived from eq. (1). The authors established a simple method to measure the interfacial tension of solder by using a wetting balance tester. ${ }^{15)}$ The measured value for an $\mathrm{Sn}-\mathrm{Pb}$ eutectic was in good accordance with the previously reported values.
Figure 5 shows the effect of additional elements on the interfacial tension on the lead-free solders used. The measured values are the interfacial tension between the soldering flux and molten solder; the flux used was the same composition as for the wetting balance test. The interfacial tension appears to be constant irrespective of the indium content. In contrast, the addition of bismuth gradually decreased the interfacial tension in both $\mathrm{Sn}-\mathrm{Ag}$ and $\mathrm{Sn}-\mathrm{Zn}$ systems.

The surface tension of binary solder can be easily calculated by using thermodynamic data. ${ }^{16,17)}$ We calculated the effect of an addition of bismuth or indium on the surface tension of tin. An addition of both silver and zinc was found to have little effect on the surface tension, which was about $0.56 \mathrm{~N} / \mathrm{m}$. The addition of bismuth gradually decreased the surface tension; the value was about $0.46 \mathrm{~N} / \mathrm{m}$ for $20 \% \mathrm{Bi}$ alloy in both $\mathrm{Sn}-\mathrm{Ag}$ and $\mathrm{Sn}-\mathrm{Zn}$ systems. In contrast, the addition of indium had little effect on the surface tension. The values were almost constant irrespective of the indium content for both $\mathrm{Sn}-\mathrm{Ag}$ and $\mathrm{Sn}-\mathrm{Zn}$ systems, at about $0.56 \mathrm{~N} / \mathrm{m}$ up to $25 \%$ In. The calculated values were somewhat greater than the values measured in Fig. 5; however, the dependency on the amount of additional elements was quite similar, where the lower values in the measurement are due to the use of soldering flux, and the value is interfacial tension accurately. It has been reported that the use of active flux lowers the interfacial tension. ${ }^{18)}$ The obtained interfacial tension shown in Fig. 5 appears to be accurate for lead-free solders under the present experimental conditions.

The contact angle is calculated by using the measured interfacial tension. Figure 6 illustrates the effect of composition on 

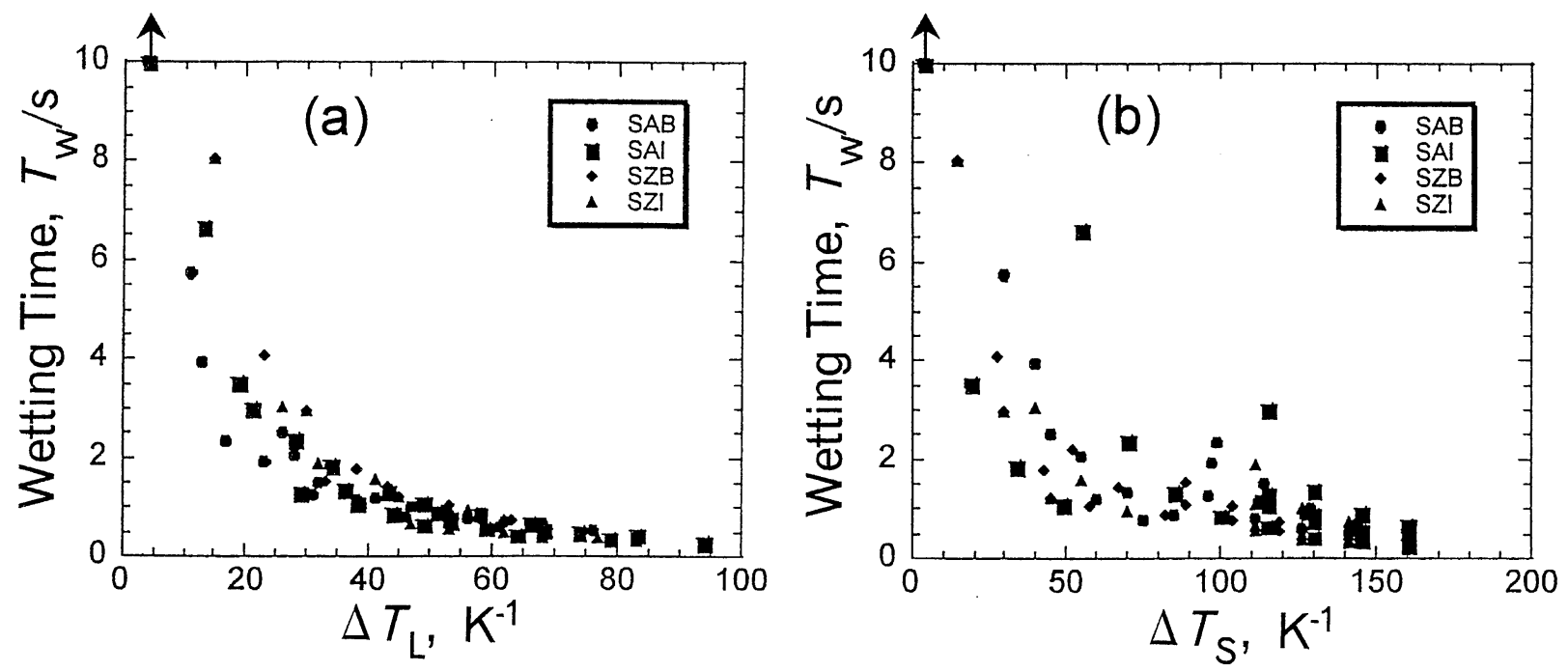

Fig. 3 Plots between wetting time and excess temperature over liquidus, $\Delta T_{\mathrm{L}}$, (a) and solidus, $\Delta T_{\mathrm{S}}$, (b).

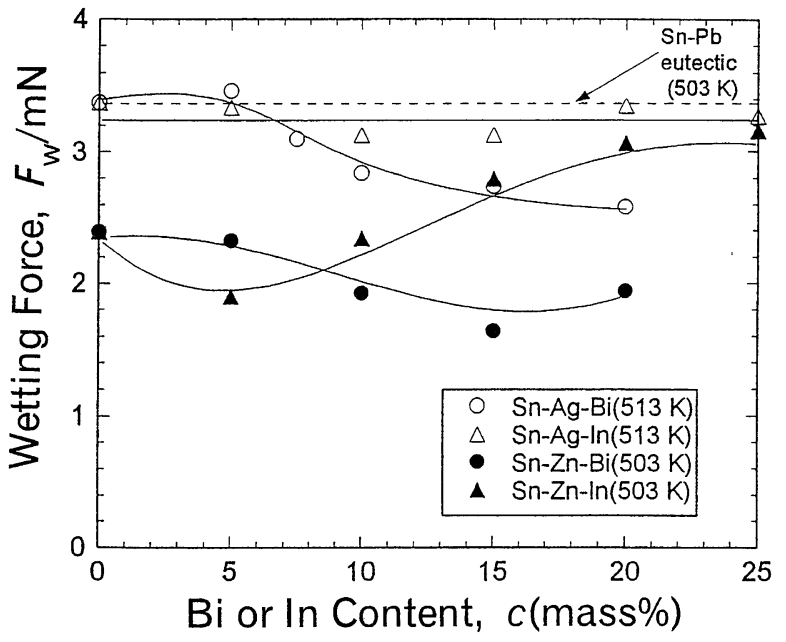

Fig. 4 Examples of wetting force measured at $503 \mathrm{~K}$ for $\mathrm{Sn}-\mathrm{Zn}$ system and at $513 \mathrm{~K}$ for $\mathrm{Sn}-\mathrm{Ag}$ system.

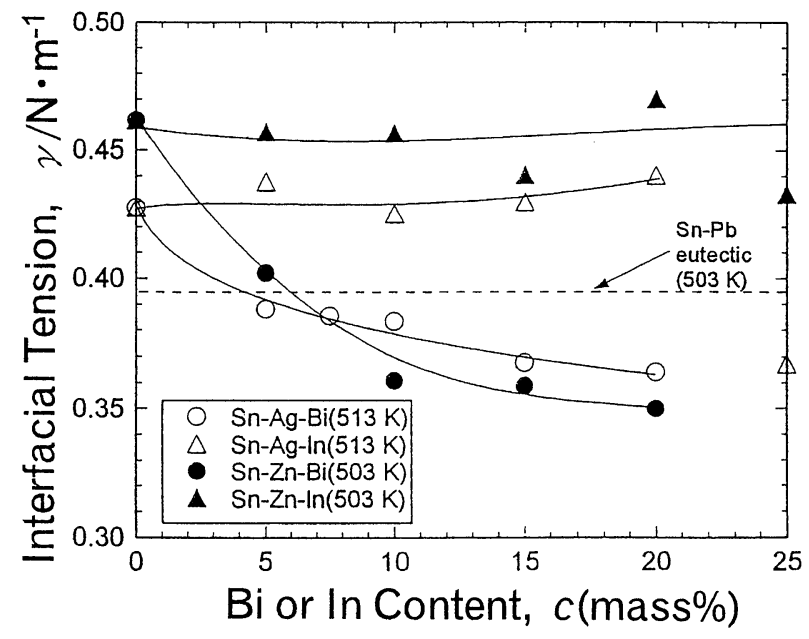

Fig. 5 Measured interfacial tension between flux and solder obtained by a wetting balance tester.

the calculated contact angle. The angle in $\mathrm{Sn}-\mathrm{Ag}$ system alloys is considerably smaller than that in $\mathrm{Sn}-\mathrm{Zn}$ systems. The addition of indium or bismuth gradually lowered the contact angle in the $\mathrm{Sn}-\mathrm{Zn}$ system. However, the addition of these elements seems to provide little improvement for wetting of

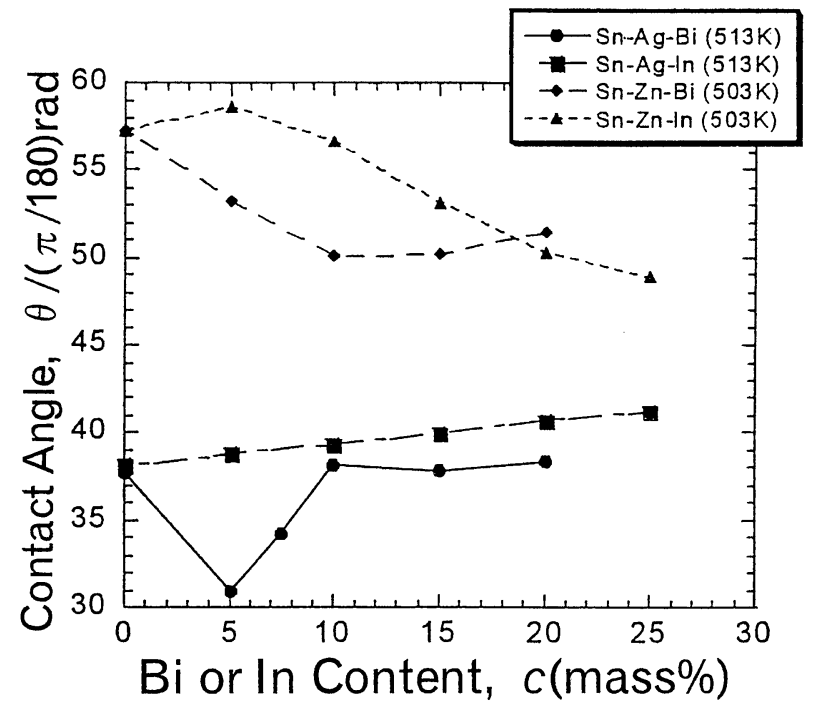

Fig. 6 Calculated contact angle by using the measured interfacial tension and wetting force.

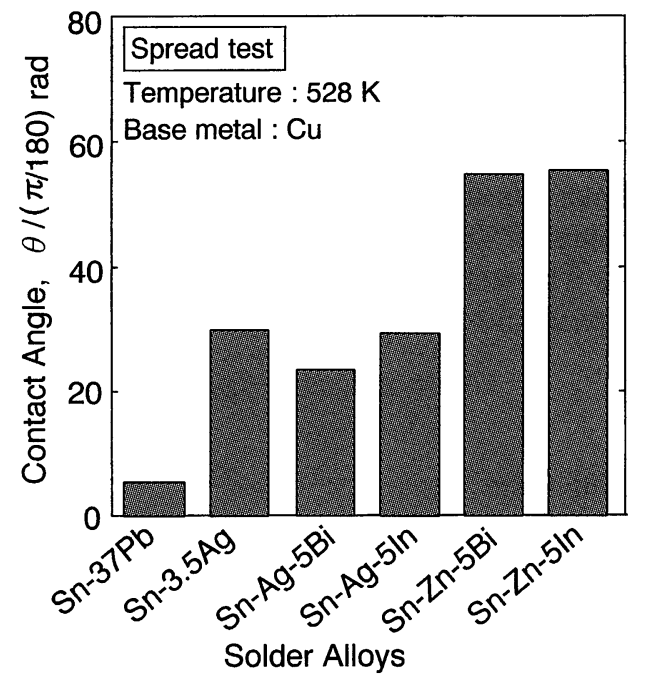

Fig. 7 Comparison of contact angle between $\mathrm{Cu}$ base metal and various solders after spread test at $528 \mathrm{~K}$.

an $\mathrm{Sn}-\mathrm{Ag}$ system. The lowest contact angle was observed in $\mathrm{Sn}-\mathrm{Ag}-5 \% \mathrm{Bi}$, for reasons that are not presently clear.

A spread test on a copper plate was conducted to confirm the calculated contact angle. Figure 7 depicts the plot of the 

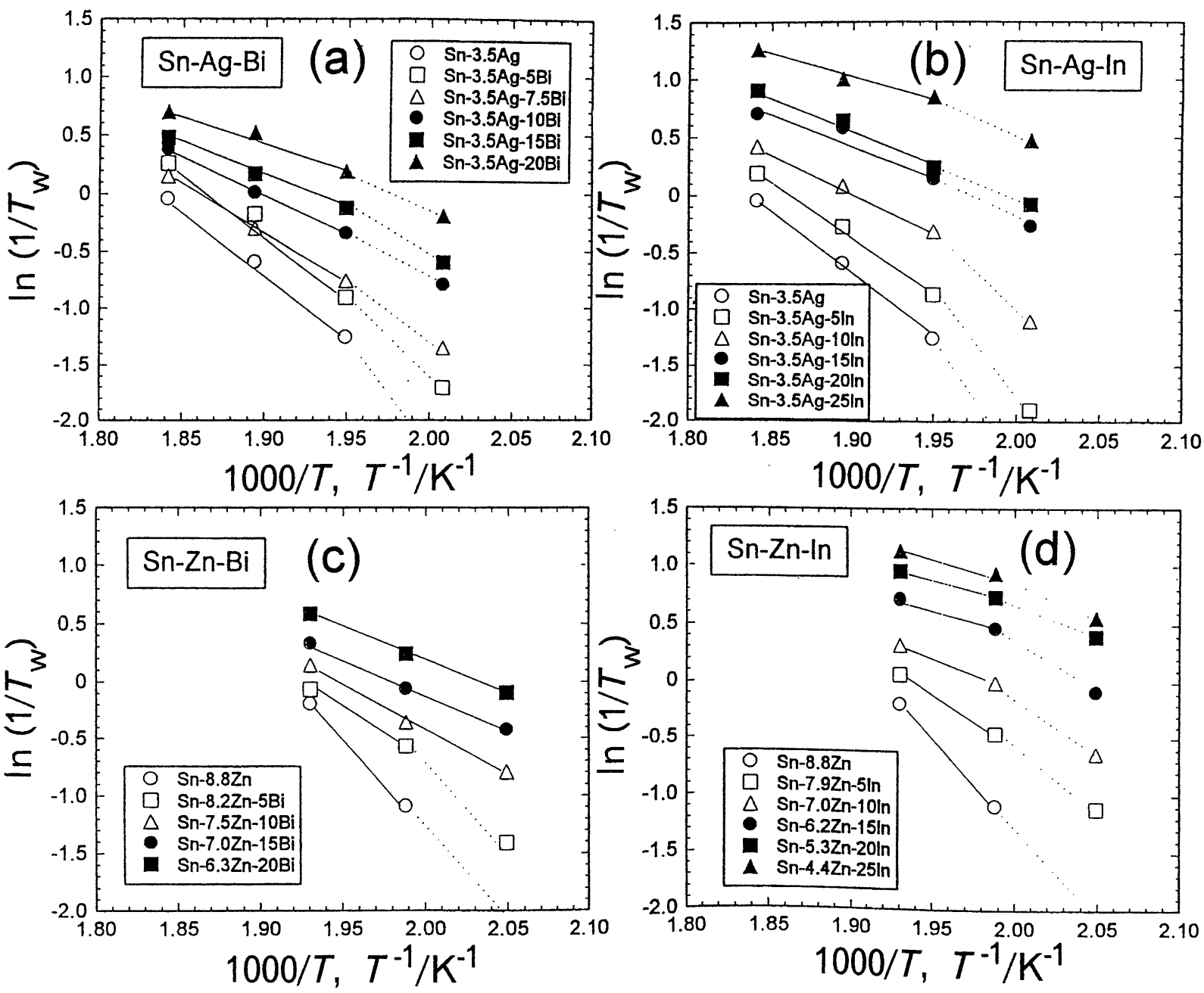

Fig. 8 Plots between logarithms of reciprocal of wetting time and reciprocal of absolute test temperature, (a) Sn-Ag-Bi, (b) Sn-Ag-In, (c) $\mathrm{Sn}-\mathrm{Zn}-\mathrm{Bi}$ and (d) $\mathrm{Sn}-\mathrm{Zn}-\mathrm{In}$.

contact angle obtained after observation on a cross section of the spread specimen. The lowest contact angle was obtained in an $\mathrm{Sn}-\mathrm{Pb}$ eutectic, and the angles in all lead-free solders were greater than that in $\mathrm{Sn}-\mathrm{Pb}$. $\mathrm{Sn}-\mathrm{Zn}$ system solders in particular exhibited extremely large values. Although the test temperature differed in the two tests, the tendency shown in Fig. 7 corresponded well to the calculated values based on the interfacial tension and wetting force. The lowest value in Sn$\mathrm{Ag}$ systems was obtained in $\mathrm{Sn}-\mathrm{Ag}-5 \mathrm{Bi}$. Although the exact values of the contact angles differed between the calculation and the experiment, the tendency was the same in both methods. The difference may be due to the different experimental methods.

The results of the contact angle clearly indicate that the best wettability was in the $\mathrm{Sn}-\mathrm{Pb}$ eutectic; it was fairly good in the $\mathrm{Sn}-\mathrm{Ag}$ system, and relatively poor in the $\mathrm{Sn}-\mathrm{Zn}$ system. We concluded that the contact angle should be derived after the wetting balance test to compare the wettability of lead-free solders; the wetting time is only useful for judging the rate of wetting, including the temperature increase process, and the wetting time cannot offer the characteristic properties of wetting.

The wetting process in the wetting balance test contains the temperature increase process of an immersed specimen. Accordingly, the process should be influenced by the reaction between the wetting front of the solid specimen and molten solder. Figure 8 gives the plots between the logarithm of the

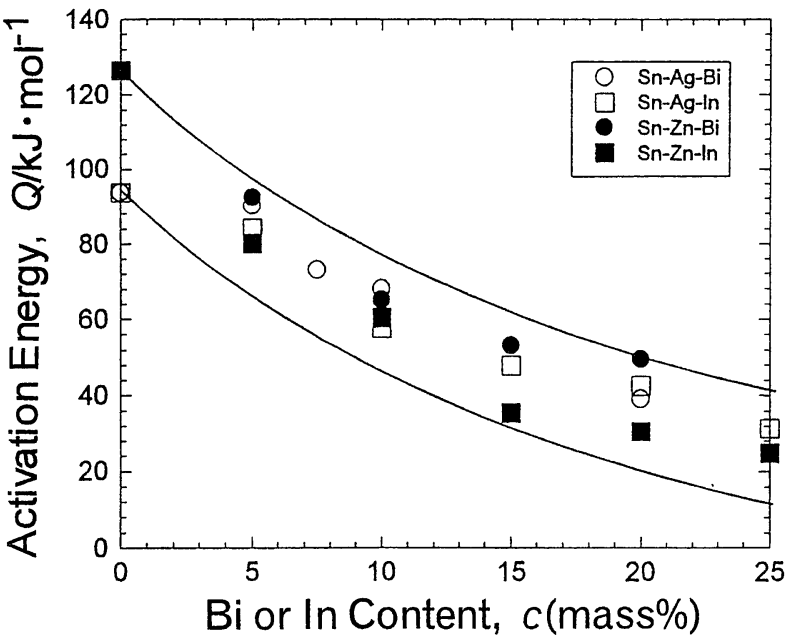

Fig. 9 Calculated activation energies for various solders, plotted against content of additional elements.

wetting rate $\left(1 / t_{\mathrm{w}}, \mathrm{s}^{-1}\right)$ and the inverse of the absolute test temperature $\left(1 / T, \mathrm{~K}^{-1}\right)$. All plots except the lowest temperature and $\mathrm{Sn}-\mathrm{Zn}-\mathrm{In}$ system exhibited a straight relationship. The apparent activation energy is calculated from the slope of the plots. The slope in the $\mathrm{Sn}-\mathrm{Zn}$-In system, was determined by plots at the two higher temperatures. The relation between the amount of additional elements and the apparent activation energy is plotted in Fig. 9. The activation energy gradually de- 
creases with increases in the amount of additional elements. If the dissolution process of solid copper into molten tin is initiated just after wetting occurs, the activation energy should be similar to the activation energy for diffusion of elements in molten tin. In alloys containing high bismuth or high indium with relatively low liquidus, the excess temperature, $\Delta T$, became large under the fixed test temperature. In this case, the molten solder will not solidify after contact with the wetting specimen. The wetting specimen immediately dissolves into molten solder and it continues to dissolve. The apparent activation energy obtained becomes close to that for diffusion in molten tin. While that value is not clear, the activation energy for self-diffusion of tin in molten tin ranges from 10.8 to $16.7 \mathrm{~kJ} / \mathrm{mol}^{19)}$ In contrast, the repetition of the dissolution process and solidification process occurs in alloys containing low bismuth or low indium with a relatively high liquidus. In such cases, the apparent activation energy becomes similar to that for diffusion in solids. The maximum value was obtained in binary systems, $\mathrm{Sn}-\mathrm{Ag}$ and $\mathrm{Sn}-\mathrm{Zn}$, where the values ranged from 95 to $125 \mathrm{~kJ} / \mathrm{mol}$. These values are very close to the activation energy for self-diffusion of tin in solid tin. ${ }^{19)}$ This indicates that the major part of the wetting process of these specimens with high melting temperatures is most likely solidification of molten solder, which could occur at the wetting front. In this case, the repetition of the re-melting and solidification process controls the wetting time. Therefore, similar activation energy for the self-diffusion of solid tin may be obtained.

\section{Conclusion}

A wetting test on lead-free solders using a wetting balance tester demonstrated that excess temperature above liquidus greatly influences the wetting time, since the test included the temperature increase stage of a specimen immersed into molten solder. It is important to use the contact angle instead of the wetting time in a wetting balance test to evaluate the wettability. For this purpose, knowing the interfacial tension between the soldering flux and the solder is necessary for converting the wetting force into the contact angle. The primary results we obtained can be summarized as follows.

(1) The single addition of bismuth or indium decreased the wetting time under the fixed test temperature in $\mathrm{Sn}-\mathrm{Ag}$ and $\mathrm{Sn}-\mathrm{Zn}$ systems. This is explained by the reduction of the liquidus temperature by the addition of elements. The large excess temperature above liquidus, (test temperature)(liquidus temperature), $\Delta T_{\mathrm{L}}$, can generate greater heat conduction in the immersed specimen, resulting in more rapid temperature rise. The shorter wetting time was obtained under the test conditions of more rapid temperature rise on the assumption that the wetting front can climb upward after reaching the critical temperature at which wetting occurs.

(2) The wettability was compared by the contact angles, and we found that the best result was obtained in the $\mathrm{Sn}-\mathrm{Pb}$ eutectic, a fairly good result was obtained in the Sn-Ag system, and the worst result was obtained in the $\mathrm{Sn}-\mathrm{Zn}$ system.
(3) The apparent activation energies for wetting obtained by the wetting balance test decreased with increases in the element contents; the values ranged from 11 to $17 \mathrm{~kJ} / \mathrm{mol}$ for the alloys with $25 \% \mathrm{In}$. These values are considered to coincide with the activation energy of self-diffusion of tin in molten tin. The apparent activation energy for $\mathrm{Sn}-\mathrm{Ag}$ and $\mathrm{Sn}-$ $\mathrm{Zn}$ binary alloys, ranged from 95 to $125 \mathrm{~kJ} / \mathrm{mol}$; the values were very close to the activation energy of self-diffusion of tin in solid tin. This indicates that two processes occur just after initiation of wetting, i.e., the dissolution process of solid copper into molten tin and repetition of the solidification and re-melting of solder at the wetting front.

\section{Acknowledgement}

The authors would like to express their gratitude to Dr. S. Hori, Prof. Emeritus at Osaka University, Mr. T. Funaki at Graduate School, Osaka University and Prof. Dr. Akira Matsunawa at the Joining and Welding Research Institute, Osaka University for helpful discussions and experimental works. The materials used were prepared by Mitsui Mining and Smelting Co. Ltd., and Harima Chemicals, Inc. Thanks also go to the Shorai Foundation for supporting our experiments.

\section{REFERENCES}

1) R. Strauss: Surface Mount Technology, (Butterworth-Heineman Ltd., Oxford, 1994) pp. 10-22.

2) C. Lea: A Scientific Guide to Surface Mount Technology, (Electrochem. Pub. Ltd., Scotland, 1988) pp. 6-41.

3) R. J. Klein Wassink: Soldering in Electronics, 2nd Edn., (Electrochem. Pub. Ltd., Scotland, 1989) pp. 10-15.

4) B. R. Allenby, J. P. Ciccarelli, I. Artaki, J. R. Fisher, D. Schoenthaler, T. A. Carroll, D. W. Dahringer, Y. Degani, R. S. Freund, T. E. Graedel, A. M. Lyons and J. T. Plewes: Circuit World 19 (1993) 18-24.

5) B. R. Allenby, J. P. Ciccarelli, I. Artaki, J. R. Fisher, D. Schoenthaler, T. A. Carroll, D. W. Dahringer, Y. Degani, R. S. Freund, T. E. Graedel, A. M. Lyons and J. T. Plewes: Circuit World 19 (1993) 25-31.

6) P. G. Harris and M. A. Whitemore: Circuit World 19 (1993) 25-27.

7) F. Hua and J. Glazer: Design and Reliability of Solders and Solder Interconnections, Ed. By R. K. Mahidhara, D. R. Frear, S. M. L. Sastry, K. L. Murry, P. K. Liaw and W. Winterbottom, (The Minerals, Metals \& Materials Society, 1997) pp. 65-73.

8) W. J. Plumbridge: J. Mater. Sci. 31 (1996) 2501-2514.

9) Lead-Free Solder Project, Final Report, (National Center for Manufacturing Science, Michigan, 1997) pp. 2-1-2-14.

10) T. Takemoto: Materia Japan 35 (1996) 320-325.

11) S. Jin and M. McCormack: J. Electronic Materials 23 (1994) 735-739.

12) I. Okamoto, T. Takemoto, M. Mizutani and I. Mori: Trans. JWRI 14 (1985) 21-27.

13) U. R. Kattner and W. J. Boettinger: J. Electronic Materials 23 (1994) 603-610.

14) C. E. T. White and H. Okamoto: Phase Diagrams of Indium Alloys, (ASM International, Ohio, 1992) pp. 315-330.

15) M. Miyazaki, M. Mizutani, T. Takemoto and A. Matsunawa: Q. J. Japan Weld. Soc. 15 (1997) 681-687.

16) R. O. Williams: CALPHAD 15 (1991) 1-5.

17) T. Iida and T. Tanaka: Reports in Japan Science and Technology Society, Commission 19, (1994), Physical-Chemistry-29.

18) C. S. McElvee: Proc. Inter NEPCON, (1980) pp. 424-427.

19) S. Nagasaki (Chief Editor): Metals Handbook, 3rd. Edn., (Maruzen, Tokyo, 1993) pp. 55-59. 